\title{
The Influence of Communication and Creativity on Decision-Making of School Principals
}

\author{
Linda Ika Mayasari \\ \{lindaika_86@yahoo.com\} \\ STKIP Kusumanegara Jakarta, Jakarta, Indonesia
}

\begin{abstract}
The objective of this research is to determine the influence of communication and creativity in the decision making process of principals at public elementary schools. Data were collected through observation, survey and by using questionnaires. Simple correlation, and linear regression were used to analyze the data obtained. 55 principals were randomly selected from a target population of 64. Using simple correlation, linear regresion, and path analysis, the data obtained were analyzed. Based on the result, the following positive direct effect can be seen between: (1) communication on decision making, (2) creativity on work decision making, (3) communication on creativity. Decision making can be improved by increasing the communication and improving creativity.
\end{abstract}

Keywords: decision making, communication, creativity

\section{Introduction}

In an educational institution, principals are among the top persons who play an important role in determining the success of education in schools. Educational institutions will be well developed once their principals carry out their jobs efectively and efficiently. One of their most crucial roles of lies in the decision-making process. A good and accurate decision will create a conducive working environment for principals and other employees.

Bad decision making leads to low motivation, and sub-standard work results. One of the causes of wrong decision making is the over population of students in schools, leading to inadequate maximazation of teaching and learning activities. Research has shown that during study hours, students are found playing and litering outside the classrooms. According to Adhi Firdaus, Head of Education Council in Bekasi, "students tend to play during study hours owing to the numerous number of students addmitted during every new academic session". "Students who This common in public schools where the principals are less concerned on the students well-being. He further stated that measures should be put in place to ensure students are accepted according to the classroms capacity. The principal has the responsibility of shouldering all responsbilities associated with the school.Therefore, the principal should be a good decision maker. 


\section{Theory framework}

Decision making is an essential organizational activity. It is closely related to a number of alternatives chosen to get the best decisions. Many problems faced by organizations is as a result of wrong decision making. . Communication is the key to social life. Humans communicate with each other in a working environment to transfer and receive information. Creativity is the ability to make or produce something new, using imaginative abilities would result to the evolution of new and useful ideas.

\subsection{Decision Making}

According to Daft [1], "decision making is the process of identifying problems and opportunities and then resolving them. It involves previous and recent collaborative effort to adopt the right strategy. ". To Schemerhorn [2], "decision making is the process of choosing a preferred course of action from a set of alternatives. But the full problem-solving process is not complete until action has been taken to do what is necessary to implement the decision and correct a performance deficiency or properly explore an opportunity". Leonard [3] said, "decision making is the process of defining problems and choosing a course of action from among alternatives. The term is often used with l"problem solving" because many supervisory decisions focus on solving problems that have occurred or are being anticipated."

\subsection{Communications}

Daft [1] stated that, "communication is the process by which information is exchanged and understood by two or more people, usually with the intent to motivate or influence individual behaviour. Honouring this distinction between sharing and proclaiming is crucial for successful management". To Tailor [4], "communication may be defined as giving, receiving, or exchanging information, opinions or ideas through writings, speeches or visually, so that the material communicated is completely understood by everyone concerned. McShane and Glinow [5] beamed that, "communication refers to the process by which information is transmitted and understood between two or more people. We emphasize the word understood because transmitting the sender's intended meaning is the essence of good communication".

\subsection{Creativity}

Accoring to Isaksen [6] , "creativity is the process of generating unique products by transforming the products. These products must be unique only to the creator, and must meet the criteria of purpose and value established ". De Graff and Lawrence [7] opines that , "creativity as a purposeful activity (or set of activities) that produces better and invaluable products, services, process, and ideas. The act of creativity can be performed by an individual, a group, or an organization, to produced the desired result". In addition, James and Sternberg [8] while viewing creativity from the utilitarian perspective defined it as a personal capability 
to create novel and appropriate solutions.. This view characterizes a creative person as one who is fully functioning, integrated, ever-growing, mentally healthy and self-actualized.

From a perspective point of view, it is defined as a person's ability to create new and appropriate solutions; a view of psychological growth. According to Mullins [9], "creativity is the application of imaginative thought which results in innovative solutions to many problems".

\section{Method}

The study used a survey method to obtain data used to analyze the research. The survey was conducted in public elementary schools. The sample population comprised of 65 principals, out of which 55 were randomly selected. The data were analyzed using path analysis technique to explain the influence of research variables. Before the path analysis was applied, significant regression and linearity test were utilized using the Liliefors-Test. In order to test the data of each research variable and the inferential statistics click the link. (https://osf.io/4mn69/)

\section{Research Findings}

\subsection{Analysis Requirement Test}

The data in this study were analyzed using path analysis with the following prerequisite tests: normality, significance and linearity test. The results of the normality test can be seen in the following table.

Table 1

\begin{tabular}{ccccc}
\hline No & Estimated Error & L $_{\text {count }}$ & Ltable & Normality Test Result \\
1 & $\mathrm{X}_{3}$ for $\mathrm{X}_{1}$ & 0,086 & 0,119 & Normal \\
2 & $\mathrm{X}_{3}$ for $\mathrm{X}_{2}$ & 0,081 & 0,119 & Normal \\
3 & $\mathrm{X}_{2}$ for $\mathrm{X}_{1}$ & 0,110 & 0,119 & Normal \\
\hline
\end{tabular}

The Result of Normality Test

Based on the table above, the results of the normality test based on the decision-making error test result (X3) for communication (X1) is $\mathrm{L}_{\text {count }}=0,086<\mathrm{L}_{\text {table }}=0,119$ at a $=0,05$. The test results illustrates that the date is normally distributed and the requirements for the analysis can be met. The calculation results for the error normality test estimated creativity of decision making as $\mathrm{L}_{\text {count }}=0,081<\mathrm{L}_{\text {table }}=0,119$ at a 0,05 . The result of the creative error normality test for communication obtained $0,110<\mathrm{L}_{\text {table }}=0,119$ at $\mathrm{a}=0,05$. It also shows that distributed data analysis can be met. The results of the estimated of the dependent and independent variable is normally distributed and indicates that the analysis requirements can 
be met. As a result of this we can conclude by saying that this analysis can easily be conducted.

\section{Hypothesis Testing}

\subsection{The Influence of Communication on Decision-Making}

Table 2. Path Coefficient of The Influence of Communication on Decision-Making

\begin{tabular}{ccccc}
\hline $\mathbf{N}$ & $\begin{array}{c}\text { Path Coefficient } \\
\left(\mathbf{p}_{31}\right)\end{array}$ & $\mathbf{t}$ count & $\boldsymbol{\alpha}=\mathbf{0 , 0 5}$ & $\boldsymbol{\alpha}=\mathbf{0 , 0 1}$ \\
& 0,493 & $4,287 * *$ & $1,674 \mathrm{~s}$ & 2,410 \\
\hline 55 & &
\end{tabular}

Based on the calculation result, it was found that the path coefficient indicated the influence of communication on decision making with 0.493 . The result of the significance test was $t_{\text {count }}=4.287>t_{\text {table }}=2.410$ at $\alpha=0.01$. The result corroborated that path coefficient was very significant. The hypothesis,stating that there is a positive direct effect of communication on decision making,is accepted. This infers good communication will lead to good decision making.

\subsection{The Influence of Creativity on Decision Making}

Table 3. Path Coefficient of The Influence of Creativity on Decision Making

\begin{tabular}{|c|c|c|c|c|}
\hline \multirow{3}{*}{$\mathbf{N}$} & \multirow{3}{*}{$\begin{array}{c}\text { Path Coefficient } \\
\left(\mathbf{p}_{32}\right) \\
0,327\end{array}$} & \multirow[b]{2}{*}{$\mathbf{t}$ count } & \multicolumn{2}{|c|}{$\mathbf{t}_{\text {table }}$} \\
\hline & & & $\alpha=0,05$ & $\alpha=\mathbf{0 , 0 1}$ \\
\hline & & $2,843 * *$ & 1,674 & 2,410 \\
\hline
\end{tabular}

Based on the result of the calculation, the magnitude of path coefficient signified that the influence of creativity on decision making is 0.327 . The results of the significance test showed $\mathrm{t}_{\text {count }}=2.843>\mathrm{t}_{\text {table }}=2.410$ at $\alpha=0.01$. The test result indicates that the path coefficient was very significant. The hypothesis,indicates that a positive direct effect of creativity on decision making, is accepted. This further suggests that good creativity will contribute to good decision making.

\subsection{The Influence of Communication on Creativity}

Table 4. Path Coefficient of The Influence of Communication on Creativity

\begin{tabular}{ccccc}
\hline $\mathrm{N}$ & Path Coefficient & $\mathbf{t}$ count & $\alpha=0,05$ & $\mathbf{t}$ table \\
& $\left(\mathrm{p}_{21}\right)$ & $5,057 * *$ & 1,674 & 2,398 \\
\hline 55 & 0,570 & & \\
\hline
\end{tabular}

Based on the calculation result, it was identified that the path coefficient which referred to the influence of communication on creativity is 0.570 . From the significance test, result it was 
obtained $\mathrm{t}_{\text {count }}=5,057>\mathrm{t}$ table $=2,398$ at $\alpha=0.01$. The test result inferred that path coefficient was very significant. The hypothesis,illustrates that there is a positive, accepted direct effect of communication on creativity. To conclude, it is convinced that the intensity of good communication leads to outstanding creativity.

The results of path analysis in this study can be described as follows.

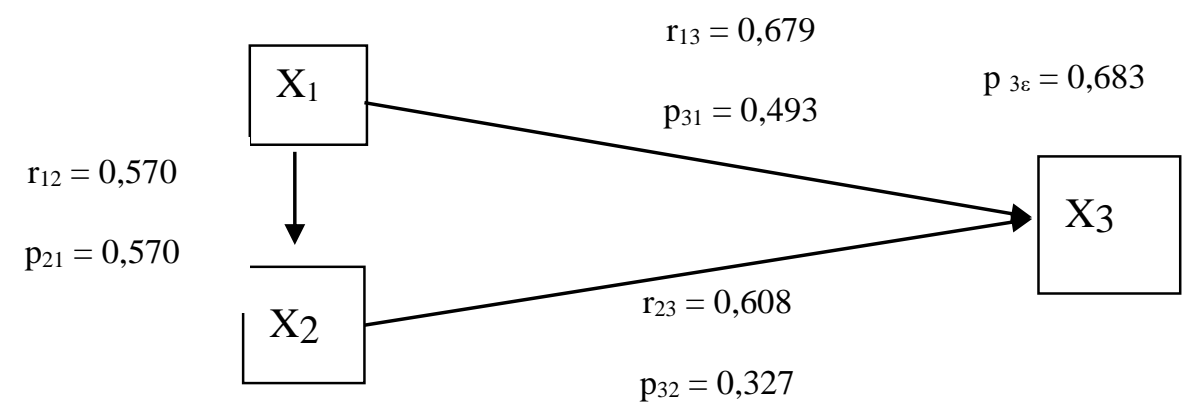

Fig 1. Path Analysis Result of The Influence of Communication (X1) and Creativity (X2) on Decision Making (X3).

\section{Discussion}

\subsection{The Influence of Communication on Decision Making}

The result of a simple correlation analysis between communication and decision making shows the correlation, and path coefficient at 0.679 and 0.493 respectively. So far, the influence of communication on decision making is positive, inferring that the better the communication, the better the decisions expected.

In connection the theory of influence of communication on decision making, Robbins and Judge [10] proposes that, "the final function of communication is to facilitate decision making. Communication provides the information individuals and groups need in order to make the right decision by transmitting the data to identify and evaluate alternative choices." This is further strengthened by Griffin and Moorhead [11] decision making theory which states that, "communication is essential to decision-making process. Information are needed to define problems, generate and evaluate alternatives, implement decisions, and control and analyze results obtained. Finally, communication expresses feelings and emotions. Organizational communication is far from merely a collection of facts and figures".

\subsection{The Influence of Creativity on Decision Making}

The result of correlation analysis between creativity and decision making collaborates with the correlation and path coefficients at 0.608 and 0.327 respectively. Therefore, its influence is regarded high and positive and is expected to contribute in helping principals make better decisions.

This is in line with Robbins and Judge [10] theory which states that, "Although the rational decision-making model will often improve decisions, creativity is also need in order 
to produce useful ideas. These are different from what's been done before but appropriate to the problem presented".

\subsection{The Influence of Communication on Creativity}

The correlation analysis result between communication and creativity indicate the correlation and path coefficients to be at 0.570 and 0.570 respectively. To this extent, their influence is significantly high and positive with better creativity.

In respect with the theory of how communication affects creativity conveyed by Isaksen [6], the result implies that, "Within this diagram, cognitive style would have the most influence during psychological and organizational processes". Communication is a very component for humans. In an effort to fulfill their needs, humans socialize (interact) with one another.. Therefore, understanding communication itself should be really considered.

\section{Conclusions}

Based on the results and analysis of this study, it can be concluded that communication and creativity has a direct positive impact on public school principals in making decisions for the betterment of their institutions. Improving good communication shall enhance their creativity level.

\section{Reference}

[1] R. L. Daft, Management, 8 ed. USA: Thomson South Western, 2008.

[2] J. R. Schemerhorn, J. G. Hunt, R. N. Osborn, and M. Uhl-Bien, Organizational Behavior 11th Edition, 11 ed. New Jersey: Wiley, 2010.

[3] J. Edwin C. Leonard, Supervision Concepts and Practices of Management,. USA: South Western Cengage Learning, 2008.

[4] S. Tailor, Communication for Business, 3 ed. England: Pearson education Limited, 1999.

[5] S. L. McShane and M. A. V. Glinow, Organizational Behavior emerging knowledge and practice for the real world, 5 ed. New York: McGraw Hill, 2010.

[6] S. G. Isaksen and K. J, The Relationship Between Cognitive Style and Individual Psychological Climate. New York: PS Group, 1998.

[7] J. DeGraff and K. A. Lawrence, Creativity at Work. USA: Wiley \& Sons, 2002.

[8] J. C. Kaufman and R. J. Sternberg, The Internationasl Handbook of Creativity. New York: Cambridge University Press, 2006.

[9] L. J. Mullins, Management and Organizational Behaviour., 7 ed. England: Pearson, 2005.

[10] S. P. Robbins and T. A. Judge, Organizational Behavior 17 ed. England: Pearson, 2013.

[11] R. W. Griffin and G. Moorhead, Organizational Behavior Managing People and Organizations. South Western: Cengage, 2014. 